\title{
EDITORIAL
}

\section{Ser hermanos más allá de la globalización. El desarrollo humano integral en Caritas in Veritate}

\author{
Consejo de Redacción
}

Palabras clave: Democracia de opinión, ética cívica, frontera, identidades complejas, identitarismos, subsidiariedad, desarrollo humano integral.

Key words: Boundary, civic ethics, complex identities, democracy of opinion, identitarisms, integral human development, subsidiarity.

Mots clés: Démocracie d'opinion, dévelopemment humain intégral, éthique civique, frontière, identités complexes, identitairismes, subsidiarité.

Esta fraternidad, ¿ipodrán lograrla alguna vez los hombres por sí solos? La sociedad cada vez más globalizada nos hace más cercanos, pero no más hermanos. La razón, por sí sola, es capaz de aceptar la igualdad entre los hombres y de establecer una convivencia cívica entre ellos, pero no consigue fundar la hermandad (Caritas in Veritate, $\left.n^{\circ} 19\right)$.

\section{Introducción}

El desarrollo es el tema central de la reciente encíclica Caritas in Veritate (CiV, a partir de ahora) del papa Benedicto XVI (julio 2009). A ella dedicamos un dossier temático en nuestra entrega de octubre-diciembre de 2009. En este editorial de la Revista de Fomento Social hemos formulado algunas tesis sobre el desarrollo tal como es propuesto por $\mathrm{CiV}$, que nos parecen más significativas, aunque no 
hemos querido ahorrar tampoco las perspectivas problemáticas o críticas que la encíclica dejó planteadas. Este editorial aparece al año de la publicación de la encíclica; con él subrayamos la importancia que ese texto tiene especialmente para quienes hacemos esta Revista y, en general, para la acción investigadora, docente, divulgadora y social de la institución responsable de la edición de la misma, INSA-ETEA de Córdoba.

Nuestro editorial "La cooperación con el desarrollo en tiempos de crisis. El caso español" de enero-marzo de 2009 ( $n^{\circ} 253$ ) trató, desde el enfoque concreto de la cooperación, sobre los Objetivos de Desarrollo del Milenio y sobre la dimensión de la solidaridad como perspectiva ética. En él decíamos que los principios de subsidiariedad y solidaridad son inspiradores de un auténtico desarrollo bajo el signo de un humanismo integral y solidario. Unos meses más tarde la encíclica CiV parecía confirmar estos enfoques y abría nuevas y esenciales perspectivas para el desarrollo, que queremos presentar con este texto. En las dos primeras tesis recogemos las afirmaciones esenciales de $\mathrm{CiV}$; en las tres tesis siguientes hacemos explícitos los fundamentos de que parte la concepción cristiana del desarrollo humano integral y en las tres últimas nos planteamos cuáles son los puntos de diálogo con otras posiciones humanistas, ideológicas o políticas ajenas a la tradición cristiana con las que nos encontramos en la búsqueda de un desarrollo humano integral. Tanto en el segundo grupo (tesis 3 a 5), como en el tercero (tesis 6 a 8) intentamos hacer una lectura que concretaremos en las conclusiones del editorial apuntando las perspectivas problemáticas o críticas de un texto abierto para el diálogo con otros. Todas las referencias a $\mathrm{CiV}$ aparecen en el editorial con números arábigos entre paréntesis, sin siglas. El texto del editorial fue cerrado el 14 de junio de 2010.

\section{Tesis I. El desarrollo es el eje central de la encíclica}

El desarrollo es el eje temático central y articulador de toda la encíclica CiV. El mismo subtítulo de la misma, Carta encíclica sobre el desarrollo humano integral en la caridad y en la verdad, pone de manifiesto la centralidad de este aspecto en el conjunto del documento. Precisamente, el segundo capítulo de CiV, que lleva por título "El desarrollo humano en nuestro tiempo" (21-33) está dedicado monográficamente a profundizar en las condiciones de un desarrollo humano integral, aunque las referencias a dicho concepto se encuentran a lo largo de todo el texto. En efecto, a lo largo de los otros capítulos se ponen de relieve, de forma recurrente, aspectos esenciales del concepto de desarrollo; sólo una visión complexiva que incluya todos esos matices daría buena cuenta de la base conceptual de la encíclica sobre el desarrollo. 
No podía ser de otra manera si se tiene en cuenta que la encíclica pretende precisamente conmemorar el cuadragésimo aniversario de la Populorum Progressio ("El desarrollo de los pueblos"; en adelante PP) de Pablo VI. Éste último ya había utilizado en 1967 el concepto de "desarrollo integral"; el desarrollo, al que Pablo VI no calificó de "humano" sino en una referencia de pasada (n. 6), debe ser integral, es decir, promover a todos los hombres y a todo el hombre. (En el texto de PP la expresión "integral" aparece cinco veces: n. 5, título de la $1^{a}$ parte, nn. $15,42,43$, y se equipara en el n. 42 a un "humanismo pleno". Se trata, pues, también de un desarrollo "humano": volveremos sobre ello.)

Partimos de la inspiración más directa de Benedicto XVI que, obviamente, no es -al menos explícitamente- el pensamiento de los científicos sociales ni siquiera de las instituciones internacionales, sino la tradición moral de la Iglesia: en este caso, el Concilio Vaticano II, Pablo VI (PP) y también Juan Pablo Il, como puede comprobarse en las continuas referencias a ellos en las notas a pie de página de CiV.

\section{Tesis 2. El desarrollo ha de ser humano e integral}

Repetimos que una de las claves de todo el texto es el concepto de desarrollo, calificado de desarrollo humano $y$, sobre todo, de desarrollo humano integral (DHI). La encíclica no habla tanto de modelos de desarrollo, que es un tema más propio de las ciencias sociales, cuanto de las condiciones éticas del desarrollo; no estamos, pues, ante un "tratado" sobre el desarrollo; se trata de una reflexión filosófico-moral, iluminada por la fe, acerca del sentido profundo del mismo. Éste es el punto de partida, el "desde dónde" de CiV.

Inspirándose en algunos textos anteriores, en particular en la Gaudium et Spes del Concilio Vaticano Il y, sobre todo, en la propia encíclica PP de Pablo VI, Benedicto XVI habla de crecimiento con matices a veces críticos; el simple crecimiento no puede identificarse con un auténtico desarrollo ("humano integral"). Para el Papa existe "buen" crecimiento y "mal" crecimiento; aunque la mayoría de las referencias son positivas, queda claro que no todo crecimiento puede ser identificado con el desarrollo. Los aspectos cualitativos del crecimiento son sostenibles y enriquecen a la persona y a los pueblos, lo que no sucede con el crecimiento antinatural y consumista (68).

Porque, naturalmente, no es lo mismo crecimiento que desarrollo. Crecer significa aumentar de tamaño; desarrollarse quiere decir expandir o utilizar la capacidad 
potencial para alcanzar un estado más completo, mayor y, sobre todo, mejor; cuando algo crece se vuelve cuantitativamente mayor, cuando se desarrolla se vuelve cualitativamente mejor. El crecimiento cuantitativo y el cualitativo, a este último nos referimos como desarrollo, siguen pautas diferentes. Puede llegar incluso a ser necesario frenar el crecimiento cuantitativo, al menos de algunos, para permitir el desarrollo cualitativo de todos. Dicho con otras palabras, no hay desarrollo sin crecimiento, pero no cualquier crecimiento es desarrollo y, menos aún, desarrollo humano. Podríamos plantearnos si en ciertos modelos y fases de desarrollo no es el "decrecimiento" la estrategia del "buen" desarrollo. Una cultura de la austeridad como revolución en la actualmente invasora cultura del consumismo no discernido es, a nuestro juicio, una opción legítima a la hora de plantear en qué consiste el "buen" desarrollo.

En Gaudium et Spes del Concilio Vaticano II, el concepto de desarrollo tiene connotaciones que remiten sin duda a "algo más que crecimiento económico"; claramente Gaudium et Spes es una de las fuentes del pensamiento de CiV sobre desarrollo.

Un párrafo de ese documento, quizá el más expresivo al respecto, describe de esta forma el "auténtico" desarrollo:

La finalidad fundamental de esta producción no es el mero incremento de los productos, ni el beneficio, ni el poder, sino el servicio del hombre, del hombre integral, teniendo en cuanta sus necesidades materiales y sus exigencias intelectuales, morales, espirituales y religiosas; de todo hombre, decimos, de todo grupo de hombres, sin distinción de raza o continente (GS, n. 64).

Está implícito en ese concepto el doble término de integral y solidario (el ser humano en todas sus dimensiones y de todos los hombres y pueblos, no unos a costa de otros). Este texto está al comienzo del capítulo tres de la segunda parte ("Algunos problemas más urgentes") de la Gaudium et Spes dedicado a la actividad socioeconómica, proporcionando de alguna manera el enfoque a todo el capítulo de esta constitución apostólica. Es importante notar que Gaudium et Spes es el primer documento oficial de la Iglesia que insiste en el desarrollo de los pueblos.

También Pablo VI mencionaba el concepto de "desarrollo solidario", que además constituye el título de la segunda parte de la encíclica, dedicada a las obligaciones de los países desarrollados respecto del sur. Previamente, en el título de la primera parte, se había utilizado el calificativo de "integral" sobre el que volveremos en seguida. En PP no se usa sino una vez (6) la expresión "desarrollo humano", pero las frecuentes referencias al humanismo en esa encíclica evocan claramente dicho 
concepto. También CiV se refiere varias veces al humanismo. Por otra parte, el concepto de "desarrollo humano integral" de CiV nos parece que es muy cercano al de "desarrollo humano" del PNUD. En efecto, en expresión de Benedicto XVI:

El desarrollo económico que Pablo VI deseaba era el que produjera un crecimiento real, extensible a todos y concretamente sostenible (21).

La expresión literal "desarrollo humano" se encuentra 32 veces en la CiV; aunque sin el adjetivo integral aparece solamente 4 veces. El adjetivo "sostenible", consagrado desde la cumbre de Río, a partir precisamente de los planteamientos conceptuales del Informe Brundtland, hace referencia a aquel desarrollo que satisface las necesidades del presente sin comprometer la satisfacción de las necesidades futuras.

En el concepto muy extendido de "desarrollo humano" que hoy se maneja, y que CiV utiliza profusamente (cfr. J. MARTíNEZ (2010) "«Caritas in veritate»: El desarrollo humano e integral en tiempo de globalización y de crisis": Sal Terrae 98, 73-92), se incluyen esos elementos esenciales que van más allá del mero crecimiento económico. Una de las fuentes de inspiración, no explícita, del concepto usado por CiV se sitúa en la estela del concepto "desarrollo humano" acuñado por el PNUD. Éste a su vez está clara y explícitamente inspirado en el pensamiento del premio Nobel de Economía, Amartya Sen, epígono de lo que algunos han llamado la familia de teorías "alternativas" del desarrollo. De pertenecer a alguna, Benedicto $\mathrm{XVI}$ estaría próximo a esta familia. Por ejemplo, en los conocidos planteamientos de Amartya Sen,

...el desarrollo humano se define como ampliación de la capacidad. A diferencia del ingreso, la capacidad es un fin, reflejado no en el insumo sino en el producto humano: en la calidad de vida de la gente. La privación se refleja en la falta de capacidad básica; cuando la gente no tiene posibilidad de llegar a ciertos niveles esenciales de logros humanos o de funcionamiento.

Dicho de otra manera, según la "filosofía" del desarrollo del Programa de Naciones Unidas para el Desarrollo (PNUD), en la estela de los planteamientos de su primer director Mahbud Ul Haq, el desarrollo humano consistiría en:

El proceso de ampliar la gama de opciones de las personas, brindándoles mayores oportunidades de educación, atención médica, ingreso y empleo, y abarcando el espectro total de opciones humanas, desde un entorno físico en buenas condiciones hasta libertades económicas y políticas (Programa de Naciones Unidas para el DesarRollo (PNUD) (1992) Informe sobre el Desarrollo Humano. Nueva York, PNUD, 18). 
Por tanto, podríamos decir que, también según estos autores, el desarrollo, para que sea humano, ha de ser integral.

A continuación exponemos los que a nuestro juicio son los fundamentos de la concepción de desarrollo humano integral de CiV. En las tres tesis siguientes aparecerá muy explícitamente formulada la concepción lógica que subyace en la encíclica, expresión coherente del pensamiento de Benedicto XVI como Papa, así como de Joseph Ratzinger como teólogo.

\section{Tesis 3. El desarrollo es una vocación y no sólo una cuestión técnica}

CiV añade un componente propio y específico al concepto de desarrollo. En la conceptualización de Benedicto XVI, el concepto de DHI incluye un "plus" que tiene que ver con la esencial apertura del ser humano a la trascendencia, y con esa dimensión de "vocación" a la que somos llamados: El desarrollo humano integral es ante todo vocación (11). ¿Qué pista abre este nuevo enfoque? El Papa no se mueve sólo en el nivel del discurso ético al uso en estas cuestiones relacionadas con el desarrollo de los individuos y de las sociedades; frente al desarrollo como mera tarea humana y ética... pregunta: ¿̇y si lo enfocamos como vocación?

Decir que el desarrollo es vocación equivale a reconocer, por un lado, que éste nace de una llamada trascendente y, por otro, que es incapaz de darse su significado último por sí mismo (16).

Aunque Benedicto XVI encuentra en la PP la inspiración para este "desbordamiento conceptual", es indudable que hay un énfasis innovador en CiV que va más allá de las alusiones de pasada en la encíclica de Pablo VI.

Lo que parece querer decir el Papa, si somos respetuosos con la literalidad de su texto, es que es Dios el que encomienda al ser humano esta tarea, que abarca tanto el plano natural como el sobrenatural (18). En ese marco, el amor y la gratuidad solidaria vendrían a ser rasgos de esta forma de "practicar" el desarrollo.

Una encíclica es un documento que no se dirige sólo a los creyentes, sino tradicionalmente (al menos desde que lo así lo hiciera Juan XXIII en 1963) a todos los hombres y mujeres de buena voluntad. Las opciones que se plantean en un documento de esta naturaleza recibirán su último fundamento de las creencias 
religiosas que engloban y sostienen la visión cristiana sobre la persona y el mundo, pero es tarea primordial de la doctrina social ofrecer con plausibilidad y racionabilidad sus propuestas para que sean accesibles a todos, creyentes, agnósticos e indiferentes. Dicho de otra forma, porque la pregunta tiene un sentido primordial, debemos razonablemente esperar que la doctrina social ofrezca respuestas a las preguntas humanas que sean aceptables y comprensibles. Para el Papa todos los seres humanos tienen capacidad de acceder a la realidad y a la verdad.

El ser humano, al responder vocacionalmente a la llamada al desarrollo, está reconociendo una llamada trascendente, que no encuentra en lo humano su significado último. Por ello ha de buscar y de respetar la verdad de la realidad. El desarrollo humano ha de ser de todo el hombre y de todos los hombres (PP 42): esa integralidad forma parte de la condición de verdad de una respuesta humana a una vocación que no nace en el ser humano sino que es recibida en la gratuidad. Toda persona está llamada a construir una respuesta humana desde su libertad, siempre nueva, siempre inaugural.

\section{Tesis 4. El desarrollo afecta a la autonomía personal y colectiva y, por tanto, a la libertad}

La Iglesia se interesa por las cuestiones económicas porque se interesa por lo humano, entendido integralmente. El cristianismo no es dualista. Por ello CiV subraya una afirmación habitual en la doctrina social católica: El desarrollo auténtico del hombre concierne unitariamente la totalidad de la persona en cada una de sus dimensiones. Ésta es la misma perspectiva de la Constitución pastoral sobre la Iglesia: la revelación cristiana nos conduce a una más penetrante comprensión de las leyes de la vida social (GS 23:5), que fue mantenida y reforzada en documentos posteriores como las encíclicas PP (1967) y Sollicitudo rei socialis (1987), ambas dedicadas al desarrollo, que es siempre un desarrollo integral. Pertenece a la verdad de la fe afirmar que la Iglesia, estando al servicio de Dios, está al servicio del mundo en términos de amor y de verdad. Como hemos afirmado en la tesis segunda, encerrado dentro de la historia, el desarrollo queda expuesto al riesgo de reducirse sólo al incremento del tener y la humanidad pierde la libertad y la valentía para estar disponible para los bienes más altos, para las iniciativas grandes y desinteresadas que la caridad universal exige (11).

Puesto que cada persona y cada pueblo están llamados a promover su propio desarrollo, la cuestión del desarrollo remite al principio ético de autonomía de 
cada persona y de cada pueblo. Éste es un tema de importancia creciente tanto en la filosofía social que se ocupa de la emergencia del sujeto como signo de nuestro tiempo, como en aquellas teorías del desarrollo que subrayan la importancia de la capacitación, del empoderamiento personal y social de cada sujeto y de cada pueblo. Hoy sólo es concebible un desarrollo que parta de los protagonistas del mismo, no que sea impuesto externamente.

Pablo VI afirmaba en PP (1967) que cada hombre debía promover su propio progreso. El hombre y la mujer tienen que tomar siempre de nuevo sus decisiones, nunca están ya tomadas por otros para nosotros; si esto ocurriese así, en efecto ya no seríamos libres. Por ello, ésta es una tarea siempre nueva. La libertad presupone que en las decisiones fundamentales cada persona y cada generación tienen un nuevo inicio.

En esta reflexión sobre el desarrollo, humano e integral, está la concepción de la vocación humana a la libertad pues en aquél está implicado no sólo un conjunto de aspectos técnicos, sino el sentido del camino humano (16). Esta reflexión de Benedicto XVI ha sido constante desde el comienzo de su pontificado. Como muestran dos textos de sus encíclicas anteriores de 2005 y 2007 respectivamente:

la construcción de un orden social, más justo (...) mediante el cual se da a cada uno lo que le corresponde, es una tarea fundamental que debe afrontar de nuevo cada generación (Deus caritas est, n. 28),

una idea que reforzó con su reflexión sobre la verdadera fisonomía de la esperanza cristiana (Spe salvi, nn. 24-25):

...un progreso acumulativo sólo es posible en lo material, (...) hay claramente una continuidad de progreso hacia un dominio cada vez mayor de la naturaleza humana. En cambio en el ámbito de la conciencia ética y de la decisión moral, no existe una posibilidad similar de incremento, por el simple hecho de que la libertad del ser humano es siempre nueva y tiene que tomar siempre de nuevo sus decisiones. No están nunca ya tomadas para nosotros por otros; en este caso, en efecto, ya no seríamos libres. La libertad presupone que en las decisiones fundamentales cada hombre, cada generación, tenga un nuevo inicio. (...) la libertad debe ser conquistada para el bien una y otra vez. La libre adhesión al bien nunca existe simplemente por sí misma. Si hubiera estructuras que establecieran de manera definitiva una determinada-buena- condición del mundo, se negaría la libertad del hombre, y por eso, a fin de cuentas, en modo alguno serían estructuras buenas. (...) la búsqueda, siempre nueva y fatigosa, de rectos ordenamientos para las realidades humanas es una tarea de cada generación; nunca es una tarea que se pueda dar simplemente por concluida. No obstante, cada generación tiene que ofrecer también su propia aportación para establecer ordenamientos convincentes de libertad y de bien, que ayuden a la generación sucesiva, como orientación al recto uso 
de la libertad humana y den también así, siempre dentro de los límites humanos, una cierta garantía también para el futuro (...). Con otras palabras: las buenas estructuras ayudan, pero por sí solas no bastan.

\section{Tesis 5. La cuestión social se ha convertido en una cuestión antropológica, que en última instancia sólo es comprensible desde la perspectiva teológica}

De la misma forma que Pablo VI señaló el alcance mundial de la cuestión social (PP 3), hoy es preciso afirmar que la cuestión social se ha convertido radicalmente en una cuestión antropológica (75):

Mientras los pobres del mundo siguen llamando a la puerta de la opulencia, el mundo rico corre el riesgo de no escuchar ya estos golpes a su puerta, debido a una conciencia incapaz de reconocer lo humano (75).

Hoy la cuestión social necesita un esclarecimiento radical y fundamental de la dignidad de la condición humana; hoy la cuestión social comienza por plantear la cuestión: ¿qué es el ser humano?

Para esta encíclica, como para la doctrina constantemente expuesta por el papa Benedicto XVI, la cuestión antropológica no tiene solución sino desde la perspectiva teologal. Por ello, la cuestión del desarrollo tiene también un origen y un fin último en Dios. Dios revela el hombre al hombre; la razón y la fe colaboran a la hora de mostrarle el bien, con tal que lo quiera ver (75). El ser humano no es su propia referencia, sino que está abierto a la verdad y contrastado por ella, la persona es un ser abierto al misterio. Ignorar esta dimensión trascendente sería un reduccionismo inaceptable que condicionaría nuestra concepción del desarrollo y condenaría finalmente a éste a su frustración definitiva. La condición humana tiene un significado profundo que sobrepasa a la propia persona. Dicho de otra forma, la condición humana no se reduce a lo que se puede percibir fenomenológicamente o lo que en cada momento es "historizado". La condición humana se desvela en un "continuum" histórico transcendental, inasible en las circunstancias cambiantes y en las concepciones efímeras de la existencia. De ahí que CiV afirme, como en otros momentos ha hecho Benedicto XVI, que la fe y la razón se aclaran mutuamente. La fe nos permite otra forma de conocer la realidad que es complementaria a la que ofrece la razón. La experiencia de apertura al misterio no empequeñece ni impide a la persona el acceso a la verdad de la realidad, antes al contrario le da una capacidad complementaria y reforzada para captar la integralidad de la misma. 
Una de las consecuencias importantes del carácter transcendente de la vocación humana que comporta el giro antropológico de la cuestión social es la afirmación en la esfera pública de la concepción integral del humanismo de raíz cristiana como nueva síntesis humanista (21), también denominada humanismo trascendental (18), humanismo verdadero (19) y humanismo nuevo (19). Este humanismo integral, precisamente por serlo, puede contribuir a la purificación de la razón y aporta su propia ayuda para que lo justo pueda ser reconocido y puesto en práctica. La Iglesia ha de servir a la formación de las conciencias y contribuir al crecimiento de la percepción de las verdaderas exigencias de la justicia y de la disponibilidad para actuar conforme a ella.

En la encíclica CiV hay muchos enfoques o puntos que hacen posible el dialogo con otras posiciones humanistas, ideológicas o políticas, ajenas a la tradición cristiana. Con muchos de estos "hombres y mujeres de buena voluntad" cooperamos los cristianos en el compromiso por un desarrollo humano integral. Estas posiciones comunes o convergentes son las que queremos presentar en las tesis que siguen.

Tesis 6. El ser humano está hecho para el don; por ello, la fraternidad es el horizonte de todo desarrollo humano integral

La caridad en la verdad remite a la "sorprendente experiencia" del don, de la gratuidad, en última instancia de Dios mismo. Sin embargo, la cultura moderna presupone implícitamente o enuncia frecuentemente un fundamento inmanente ( $¡ \circ$ ninguno!) del ser humano: la errónea convicción de ser [el ser humano] el único autor de sí mismo, de su vida y de la sociedad (34), una presunción fruto de la cerrazón egoísta en sí mismo, que remite al pecado original como expresión de esa cerrazón y como realidad. La consecuencia la hace explícita la misma encíclica:

Creerse autosuficiente y capaz de eliminar por sí mismo el mal de la historia ha inducido al hombre a confundir la felicidad y la salvación con formas inmanentes de bienestar material (34).

Esta comprensión autocentrada elimina un poderoso factor que contribuye al desarrollo: la esperanza cristiana, un poderoso recurso social al servicio del desarrollo humano integral (34). Esta exclusión, cuando se produce, tiene consecuencias graves sobre el propio desarrollo (PP 48). 
El don es, a su vez, la fuerza que funda la comunidad, y unifica a los hombres de manera que no haya barreras o confines (35). El don es la condición de existencia de una comunidad fraterna. Esta fraternidad será el espacio de una amistad cívica, así como de la amistad teologalmente fundada que solemos denominar comunión. Ambas pueden ser consideradas dos dimensiones de una misma realidad.

La sociedad global nos hace más cercanos, pero no más hermanos (19). En una humanidad cada vez más relacionada e interactiva, la vecindad debe transformarse en comunión (53): lo que está en juego es la necesidad de alcanzar una auténtica fraternidad (20). Todo aquello que conduzca a este fin contribuirá a fundar un desarrollo auténtico o integral.

La categoría comunión, correlato de la de fraternidad, alcanza una relevancia económica, social, cultural y política significativa: el desarrollo de los pueblos depende sobre todo de que se reconozcan como parte de una sola familia, que colabora con verdadera comunión y está integrada por seres que no viven simplemente uno junto al otro (53). CiV sugiere indicativamente algunos ejemplos de esa economía del don, como son la banca ética, las empresas de economía de comunión, etc. Un desarrollo auténtico o integral debe realizarse en la construcción de una fraternidad humana que tenga como forma de relación la comunión que permite que nos reconozcamos como parte de una sola familia humana: nunca más simplemente uno junto al otro, sino todos responsables de todos, de todo el hombre y de todos los hombres. La comunidad fraterna es el modelo de la comunidad humana y el anticipo de la unidad de la familia humana (53).

\section{Tesis 7. Un desarrollo humano integral encuentra en el verda- dero humanismo integral el fundamento del desarrollo}

La fraternidad implica y exige a su vez, la aceptación y el despliegue de la lógica del don. Esta lógica del don, propia de la fraternidad, convive con otras lógicas que también son necesarias para un desarrollo humano integral y complementarias entre sí: la de la justicia, más propia de la política o del Estado (34), y la lógica de la equivalencia o mercantil, más propia del mercado (35):

Indudablemente la vida económica tiene necesidad del contrato para regular las relaciones de intercambio entre valores equivalentes. Pero necesita igualmente leyes justas y formas de redistribución guiadas por la política, además de obras caracterizadas por el espíritu del don (37). 
Estas lógicas complementarias se necesitan, aunque en ciertos ámbitos sean más relevantes unas frente a otras. Las tres lógicas necesitan personas abiertas al don, pues si no fuese así, es decir si la lógica del mercado (dar para tener) y la lógica del Estado (dar por deber) se pusiesen de forma excluyente de acuerdo para mantener el monopolio de sus respectivos ámbitos de influencia, la solidaridad se debilitaría (39) y la victoria sobre la pobreza y la desigualdad se retrasaría o quedaría comprometida. Para alcanzar ésta cree que es necesaria

la apertura progresiva en el contexto mundial a formas de actividad económica caracterizada por ciertos márgenes de gratuidad y comunión (39).

No obstante, como se explica en la siguiente tesis, estas lógicas son asimétricas en cuanto pueden configurar un orden social justo común para todos. Por ello queremos subrayar que junto a la apertura progresiva a la economía del don, el cristianismo no podrá nunca ausentarse del esfuerzo por incidir en la reforma del sistema en su conjunto, especialmente desde el centro del mismo.

El humanismo no es sólo integral porque la persona esté abierta a la transcendencia, sino porque aquel Dios que la habita es también quien llama al hombre con una vocación trascendente. El humanismo es integral no sólo por reconocer una dimensiones psíquica y pneumática de la realidad humana, sino porque afirma, aun cuando lo haga con lenguaje secular y analógico, que la realidad está abierta a una infinitud trascendente. A partir de esta concepción de la realidad, el desarrollo debe orientarse siempre de acuerdo con la verdad de la realidad.

CiV propone ese fundamento, común para todos los hombres y mujeres de nuestro tiempo comprometidos con el desarrollo, basado en un humanismo que sea integral, expresión de una nueva síntesis humanista (21). CiV en última instancia está planteando el desarrollo como cuestión antropológica e invita a un diálogo en el ágora pública, en el "patio de los gentiles" (discurso de Benedicto XVI, 21-XII2009) donde sea posible y plausible reconocer el drama de un humanismo ateo y la veracidad racional y plausible de un humanismo integral, un humanismo abierto a la transcendencia y al Transcendente. Desde ese punto de partida expresó una invitación dirigida en primer lugar a los cristianos que es válida para proponer esa nueva síntesis humanista a la que nos venimos refiriendo:

Pero considero importante sobre todo el hecho de que también las personas que se declaran agnósticas y ateas deben interesarnos a nosotros como creyentes. Cuando hablamos de una nueva evangelización, estas personas tal vez se asustan. No quieren verse a sí mismas como objeto de misión, ni renunciar a su libertad de pensamiento y de voluntad. Pero la cuestión sobre Dios sigue estando también en ellos, aunque 
no puedan creer en concreto que Dios se ocupa de nosotros. (...) debemos tratar de mantener viva esta búsqueda; debemos preocuparnos de que el hombre no descarte la cuestión sobre Dios como cuestión esencial de su existencia; preocuparnos de que acepte esa cuestión y la nostalgia que en ella se esconde. Me vienen aquí a la mente las palabras que Jesús cita del profeta Isaías, es decir, que el templo debería ser una casa de oración para todos los pueblos (cf. Is 56, 7; Mc 11, 17). Él pensaba en el llamado "patio de los gentiles", que desalojó de negocios ajenos a fin de que el lugar quedara libre para los gentiles que querían orar allí al único Dios, aunque no podían participar en el misterio, a cuyo servicio estaba dedicado el interior del templo. Lugar de oración para todos los pueblos: de este modo se pensaba en personas que conocen a Dios, por decirlo así, sólo de lejos; (...) creo que la lglesia debería abrir también hoy una especie de "patio de los gentiles" donde los hombres puedan entrar en contacto de alguna manera con Dios sin conocerlo y antes de que hayan encontrado el acceso a su misterio, a cuyo servicio está la vida interna de la lglesia. Al diálogo con las religiones debe añadirse hoy sobre todo el diálogo con aquellos para quienes la religión es algo extraño, para quienes Dios es desconocido y que, a pesar de eso, no quisieran estar simplemente sin Dios, sino acercarse a él al menos como Desconocido. (discurso de Benedicto XVI, 21 -XII-2009)

\section{Tesis 8. CiV propone la lógica sistémica de la fraternidad ca- paz de humanizar las predominantes lógicas económicas y sociales}

La doctrina social de la Iglesia ha buscado recientemente, al menos desde la encíclica programática de Pablo VI Ecclesiam suam (1964), cierta "equidistancia", un intento, seguramente ilusorio, de "buenas relaciones" con el mundo contemporáneo al que ya no impugna ideológicamente como era tradicional en la doctrina social clásica. CiV continúa en esa misma actitud y tiende la mano para "complementar" con "otra lógica", más "concurrente" que "alternativa", las lógicas modernas que inspiran los diversos subsistemas que nuclean las diferentes instancias institucionales del entero sistema político, económico y social. Se entiende así por qué CiV renuncia a valorar críticamente estas instancias sistémicas e incluso a dar criterios concretos para conformar o reformar los respectivos subsistemas institucionales (políticos, jurídicos, económicos y sociales). CiV se limita a yuxtaponer "otra lógica" inspirada en la ética iluminada por la fe, esto es, la ética del don, la gratuidad y la fraternidad. Para CiV estos son sólo, aunque no secundariamente, elementos de "otro subsistema moral" que sólo se propone con el propósito de reorientar los aludidos subsistemas institucionales conformadores del entero sistema económico, social y político. 
Esta propuesta ciertamente es una novedad de este documento. Con ella la doctrina social contribuye a superar el déficit ético de los procesos y proyectos de desarrollo humano. En ese punto CiV hace valer su empeño crítico hacia las aludidas instancias institucionales que vertebran el entero sistema económico y social. La encíclica estima que estas instancias o subsistemas están escasamente humanizadas por cuanto están afectadas de un desarrollo humano "deficitario", sea unas veces por su neutralidad o inhibición políticas, sea en otras circunstancias por su hiperideologización opuesta a este modelo de desarrollo humano integral. El desafío estriba en humanizar todos esos subsistemas con sus correspondientes lógicas sistémicas. El medio para alentar esa humanización radica en la levadura del don y la gratuidad, en definitiva, en la tarea de la fraternidad.

En suma, la propuesta de esa "otra lógica sistémica" del don y la gratuidad, que hunde sus raíces en la fraternidad como "principio fracasado de la modernidad", no se propone como "alternativa" a las otras lógicas "excluyentes de lo humano", deshumanizadoras, sino como humilde y eficaz "levadura" susceptible de fermentarlas y de humanizarlas integralmente. Esta "otra lógica" acude en remedio del déficit estructural de humanidad integral $y$, en definitiva, alienta de este modo implícito a que renuncien a la nunca practicada neutralidad ideológica o política y se impliquen en la gran tarea del desarrollo humano integral. Parece que la fraternidad es la vía por la que CiV busca que las clásicas lógicas que gobiernan el mundo, esto es las estructuras y los hábitos que rigen el entero sistema social, económico, mercantil, político, judicial, empresarial, administrativo o estatal, se vean fermentadas y comprometidas con el desafío de construir "otro mundo posible" bajo la bandera del desarrollo humano integral.

No corresponde a CiV programar políticas concretas para lograr la efectiva humanización integral del sistema político, económico y social, pero sí dar pistas y sugerir criterios orientadores para alentar un nuevo impulso del pensamiento para comprender mejor lo que implica ser una familia (53) y promover ideas, vías políticas y estrategias de acción que articulen políticas de desarrollo humano integral. La gran propuesta que, como desafío intelectual y moral, hace a los pensadores de reflexión profunda (19) estriba en hibridizar o imbricar-no sólo irradiar, sino comprometer- las lógicas económicas y sociales dominantes hoy en el mundo con la "lógica del corazón", núcleo de convergencia y punta de lanza conjunta de la fe y la razón. 


\section{Conclusión en forma de preguntas}

¿Sólo se puede llegar a un conocimiento completo de la realidad desde la fe cristiana? La lectura de CiV nos deja una pregunta abierta, casi como una herida. En la encíclica parece que el humanismo pleno, fundamento de un desarrollo humano integral y solidario, se identifica con el humanismo cristiano, aunque queden suficientes puertas abiertas para entender que no es necesariamente esa la visión exclusiva de la encíclica. Estos planteamientos de Benedicto XVI no pueden menos de suscitar la pregunta de cómo hacerlos aceptables por las personas que no comparten la fe cristiana. Que, como afirmamos en la pregunta inicial, sólo se llegue a conocer la realidad desde la fe cristiana, èsignifica una descalificación del "no creyente" en las tareas del desarrollo y de la construcción de una humanidad más justa y solidaria, compartidas con los creyentes? Para Benedicto XVI la ampliación del horizonte que significa la fe cristiana, no implicaría ningún recorte para el desarrollo del ser humano o de los países; el Papa lo concibe como una ampliación de posibilidades que se abren, inspiradas por el amor, y que se traducen en un mucho mayor énfasis en las dimensiones de gratuidad y de don, incluso en las compartidas con los no creyentes, actuaciones encaminadas al desarrollo humano. A nuestro juicio, también para quienes no comparten la visión que proporciona la fe cristiana, el desarrollo es una vocación humana. Para poder dialogar desde dentro del cristianismo deberíamos pensar detenidamente lo que hemos expuesto al final de la tesis séptima.

¿Es la realidad fuente de conocimiento o hay una verdad más esencial que es la que garantiza la autenticidad del conocimiento? CiV afirma que no ha habido ruptura en la doctrina social de la Iglesia, pero tras su lectura nos parece retornar a cierta concepción más deductiva de aquélla, próxima a la denominada "metafísica social". Ya con Juan XXIII en Pacem in terris, pero sobre todo con el Concilio Vaticano Il y la enseñanza social de Pablo VI, la doctrina social dio un giro hacia una enseñanza más inductiva, que recibía la aportación de las ciencias sociales y de la experiencia plural de las Iglesias locales. CiV, sin embargo, parece un texto bien ambientado para el mundo académico del contexto occidental, el llamado "norte". Parece depender de una visión etnocéntrica que es poco participativa, poco receptiva de búsquedas que se vienen realizando en el "sur" tanto en las comunidades eclesiales, como en los nuevos movimientos sociales; por último, la ausencia de la referencia a las mujeres como actores del desarrollo también es un signo de esta preocupación. Aunque en CIV se trata de varias formas y de manera sugerente la problemática ecológica, no deberíamos olvidar que un humanismo pleno, base de un desarrollo humano e integral, hoy no es posible sin integrar la perspectiva de la tierra. Aceptando la cautela de CiV ante un naturalismo idolátrico 
de la tierra, podemos afirmar sin ambages: "nunca más" un desarrollo humano integral sin la tierra o contra la tierra.

¿Seguirá siendo capaz la doctrina social de incidir en la reforma del sistema en su conjunto, especialmente desde el centro del mismo? El giro antropológico que marcará este documento no debería hacernos olvidar que algunas de las afirmaciones más fuertes y fecundas de la doctrina social desde sus orígenes, pero especialmente después de la segunda guerra mundial, se hicieron en la pretensión de influir en el centro de los sistemas económicos, sociales y políticos. Si antes de 1945 fueron las sucesivas orientaciones ante el liberalismo y el socialismo y la confrontación ante los totalitarismos y autoritarismos, después de la segunda guerra mundial tuvo lugar la promoción y el apoyo del llamado modelo social europeo, ante el comunismo estatista y ante el capitalismo sin límites. Estos siguen siendo, a nuestro juicio, los verdaderos lugares del debate social contemporáneo. El giro antropológico no debiera convertirse en una reducción antropológica de la doctrina social.

Nuestra pretensión en este comentario editorial ha sido responder modestamente a la necesidad de pensamiento, pues seguimos convencidos, que aunque el subdesarrollo tiene una causa más importante aún que la falta de pensamiento: es "la falta de fraternidad entre los hombres y entre los pueblos" (19, citando PP 66), el pensamiento profundo es esencial para un adecuado enfoque que trascienda el inmediatismo ante la realidad (CiV 3-4) y contribuya a un desarrollo humano duradero e integrador. Si para alcanzar el desarrollo hacen falta pensadores de reflexión profunda que busquen un humanismo nuevo, que permita al hombre moderno hallarse a sí mismo, nuestro intento quiere insertase en esta estela y abrir preguntas y espacios para un diálogo que hoy sigue siendo más urgente que nunca y, por tanto, necesario: una acción, un pensamiento y un diálogo que postulamos y promovemos como cristianos al servicio de sus hermanos, en los puntos desde se juegan estos su existencia y su porvenir. (Pablo VI (1971) Octogesima adveniens, n. 51). 